Бальчугов Алексей Валерьевич, Д.Т.н., профессор, Ангарский государственный технический университет, e-mail: balchug@mail.ru

Важенин Михаил Николаевич, магистрант, Ангарский государственный технический университет

Кустов Борислав Олегович, аспирант, Ангарский государственный технический университет, e-mail: fresh_33@mail.ru ИСПЫТАНИЯ ЛАБОРАТОРНОЙ УСТАНОВКИ ДЛЯ ИССЛЕДОВАНИЯ ТЕПЛОПЕРЕДАЧИ НА ГОРИЗОНТАЛЬНОЙ ТЕПЛООБМЕННОЙ ТРУБЕ Balchugov A.V., Vajenin M.N., Kustov B.O.

\title{
TESTING LABORATORY UNIT FOR RESEARCH ON HEAT TRANSFER OF HORI- ZONTAL HEAT EXCHANGE TUBE
}

\begin{abstract}
Аннотация. Выполнены испытания лабораторной установки для исследования новых методов интенсификации теплопередачи. Экспериментально определенные коэффрициенты теплопередачи хорошо согласуются с рассчитанными по известным уравнениям, что свидетельствует о надежности применяемых методов исследования.

Ключевые слова: интенсификация теплопередачи, теплообменная труба, лабораторная установка.

Abstract. Tests of a laboratory setup for the study of new methods of heat transfer enhancement were performed. The experimentally determined heat transfer coefficients are in good agreement with those calculated by known equations, which indicates the reliability of the research methods used.

Key words: heat transfer intensification, heat exchange tube, laboratory installation.

Создана лабораторная установка для исследования различных методов интенсификации теплопередачи на горизонтальной теплообменной трубе. Перед проведением исследований лабораторную установку требуется испытать в условиях, для которых в литературе имеются надежные эмпирические уравнения для расчета коэффрициентов теплопередачи [1]. В случае допустимых отклонений экспериментальных и расчетных значений коэффрициентов теплопередачи можно сделать вывод о готовности установки к лабораторным исследованиям новых способов интенсификации теплопередачи и о надежности и достоверности используемых методов измерения. Схема лабораторной установки приведена на рис. 1. Установка состоит из горизонтальной теплообменной трубы (1), емкости (2) с водой объемом 40 литров, приемной емкости (3), вентиля (4), электронагревателя (5), опор (6), соединительных шлангов, ротаметра (7), термометров (8-10). Разность уровней воды в емкостях (2) и (3) составляет 1,8 м. Уровень горизонтальной трубы над уровнем пола - 1 м. Внутри теплообменной трубы самотеком течет поток горячей воды из емкости (2) в емкость (3). Теплообменная труба охлаждается снаружи атмосферным воздухом при свободной конвекции.
\end{abstract}




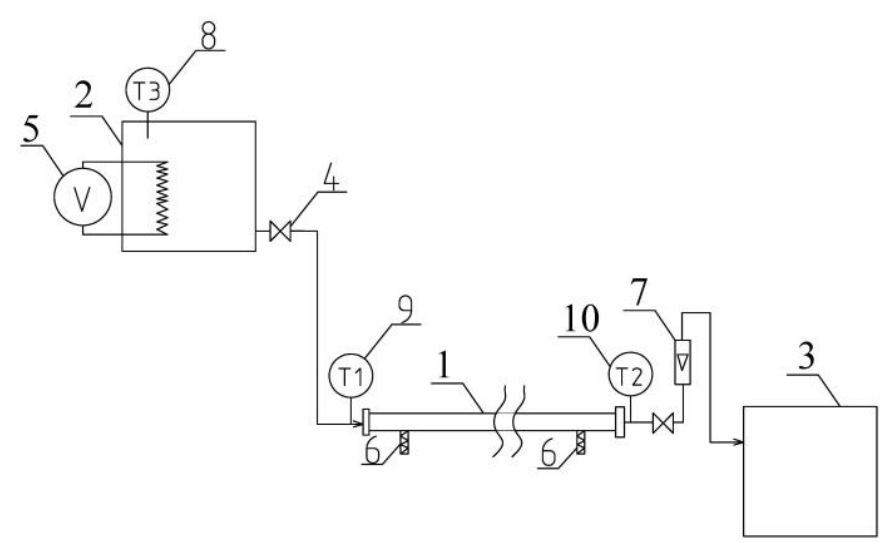

Рис. 1 - Лабораторная установка

Методика экспериментов состоит в следующем. Емкость (2) заполняется водой до уровня $80 \%$. Включается в сеть электронагреватель. Вода в емкости (2) доводится до кипения. Открывается вентиль (4), и вода самотеком начинает поступать по теплообменной трубе через ротаметр (7) в емкость (3). В емкости (2) поддерживается постоянный уровень воды за счет подачи в емкость свежей горячей воды. Расход регулируется с помощью вентиля (4). После того, как установка выходит на установившийся режим, при котором показания термосопротивлений (9) и (10) перестают изменяться во времени, снимаются показания термосопротивлений и записываются в журнал. В ходе эксперимента снимается и фиксируется расход воды, температура воды на входе и выходе из теплообменной трубы, температура окружающего воздуха, температура воды в емкости (2), разница уровней воды в емкостях (2) и (3).

В результате выполненных экспериментов установлено, что при расходе воды 26,3 кг/ч; начальной температуре воды в трубе $t_{н}=92,2{ }^{\circ} \mathrm{C}$; конечной температуре воды в трубе $t_{k}=90,4{ }^{\circ} \mathrm{C}$; длине трубы $l=1,5 \mathrm{~m}$; наружном диаметре трубы $\mathrm{d}_{\mathrm{H}}=0,035 \mathrm{~m}$; температуре атмосфрерного воздуха $\mathrm{t}_{\mathrm{B}}=26{ }^{\circ} \mathrm{C}$ коэфффициент теплопередачи составил $\mathrm{K}=5,27 \mathrm{BT} /\left(\mathrm{M}^{2}\right.$ град). Для этих же условий рассчитан коэффрициент теплопередачи по известным уравнениям из работы [2], он составил $\mathrm{K}=4,82$ $\mathrm{Bт} /\left(\mathrm{M}^{2}\right.$ град), что на 8,54 \% ниже экспериментально определенного коэфрфициента теплопередачи. Таким образом, экспериментальное значение коэффициента теплопередачи не существенно отклоняется от теоретического, что позволяет сделать вывод о надежности применяемых методов исследования. Разработанная лабораторная установка может быть использована для исследования новых методов интенсификации теплопередачи.

\section{ЛИТЕРАТУРА}

1. Захаренков А.В., Комов А.Т., Варава А.Н., Дедов А.В., Болтенко Э.А., Мясников В.В., Ильин А.В. Экспериментальный стенд для исследования теплогидравлических характеристик модельных элементов тепловыделяющих сборок // Вестник МЭИ. - №2. - 2013. - с. 39-45.

2. Павлов К.Ф., Романков П.Г., Носков А.А. Примеры и задачи по курсу процессов и аппаратов химической технологии. Учебное пособие для вузов. Л. Химия, 1981. 576 C. 